\title{
The neuropathology of autism: defects of neurogenesis and neuronal migration, and dysplastic changes
}

\author{
Jerzy Wegiel · Izabela Kuchna $\cdot$ Krzysztof Nowicki $\cdot$ Humi Imaki · Jarek Wegiel • Elaine Marchi • \\ Shuang Yong Ma - Abha Chauhan - Ved Chauhan - Teresa Wierzba Bobrowicz • Mony de Leon • \\ Leslie A. Saint Louis • Ira L. Cohen • Eric London • W. Ted Brown • Thomas Wisniewski
}

Received: 12 November 2009/Revised: 5 February 2010/Accepted: 9 February 2010/Published online: 3 March 2010

(C) The Author(s) 2010. This article is published with open access at Springerlink.com

\begin{abstract}
Autism is characterized by a broad spectrum of clinical manifestations including qualitative impairments in social interactions and communication, and repetitive and stereotyped patterns of behavior. Abnormal acceleration of brain growth in early childhood, signs of slower growth of neurons, and minicolumn developmental abnormalities suggest multiregional alterations. The aim of this study was to detect the patterns of focal qualitative developmental defects and to identify brain regions that are prone to developmental alterations in autism. Formalin-fixed brain hemispheres of 13 autistic (4-60 years of age) and 14 agematched control subjects were embedded in celloidin and cut into 200- $\mu \mathrm{m}$-thick coronal sections, which were stained with cresyl violet and used for neuropathological evaluation. Thickening of the subependymal cell layer in two brains and subependymal nodular dysplasia in one brain is
\end{abstract}

Jerzy Wegiel $(\bowtie) \cdot$ I. Kuchna · K. Nowicki · H. Imaki ·

Jarek Wegiel - E. Marchi - S. Y. Ma - T. Wisniewski

Department of Developmental Neurobiology,

NYS Institute for Basic Research in Developmental Disabilities (IBR), 1050 Forest Hill Road, Staten Island, NY 10314, USA

e-mail: jerzy.wegiel@omr.state.ny.us

M. de Leon - L. A. S. Louis · T. Wisniewski

Department of Neurology,

New York University School of Medicine, New York, NY, USA

M. de Leon - L. A. S. Louis - T. Wisniewski

Department of Pathology,

New York University School of Medicine, New York, NY, USA

M. de Leon - L. A. S. Louis · T. Wisniewski

Department of Psychiatry,

New York University School of Medicine, New York, NY, USA

A. Chauhan - V. Chauhan

Department of Neurochemistry, IBR, Staten Island, NY, USA indicative of active neurogenesis in two autistic children. Subcortical, periventricular, hippocampal and cerebellar heterotopias detected in the brains of four autistic subjects (31\%) reflect abnormal neuronal migration. Multifocal cerebral dysplasia resulted in local distortion of the cytoarchitecture of the neocortex in four brains $(31 \%)$, of the entorhinal cortex in two brains $(15 \%)$, of the cornu Ammonis in four brains and of the dentate gyrus in two brains. Cerebellar flocculonodular dysplasia detected in six subjects (46\%), focal dysplasia in the vermis in one case, and hypoplasia in one subject indicate local failure of cerebellar development in $62 \%$ of autistic subjects. Detection of flocculonodular dysplasia in only one control subject and of a broad spectrum of focal qualitative neuropathological developmental changes in 12 of 13 examined brains of autistic subjects (92\%) reflects multiregional dysregulation

\section{T. W. Bobrowicz}

Department of Neuropathology,

Institute of Psychiatry and Neurology, Warsaw, Poland

I. L. Cohen - E. London

Department of Psychology, IBR, Staten Island, NY, USA

W. T. Brown

Department of Human Genetics, IBR, Staten Island, NY, USA

L. A. S. Louis

Corinthian Diagnostic Radiology, New York, NY, USA

M. de Leon

Nathan S. Kline Institute for Psychiatric Research,

Orangeburg, NY, USA 
of neurogenesis, neuronal migration and maturation in autism, which may contribute to the heterogeneity of the clinical phenotype.

Keywords Autism - Developmental neuropathology · Subependymal nodular dysplasia - Heterotopia . Dysplasia

\section{Introduction}

Autism is characterized by a broad spectrum of clinical manifestations, including (a) qualitative impairments in reciprocal social interactions, (b) qualitative impairments in verbal and nonverbal communication, (c) restricted repetitive and stereotyped patterns of behavior, interests and activities and (d) onset prior to the age of 3 years [1]. In most cases, the etiology is unknown, and patients are diagnosed with idiopathic or non-syndromic autism [10, 43]. About $70 \%$ of individuals with idiopathic autism have essential autism, defined by the absence of physical abnormalities, but in 30\%, complex autism with dysmorphic features such as microcephaly and/or a structural brain malformation is diagnosed [79]. In 5-10\% of cases, autism is diagnosed in association with other disorders such as fragile X syndrome, Rett syndrome, Down syndrome, and tuberous sclerosis [94, 105]. Intellectual impairments, defined as intelligence quotient (IQ) scores less than 70, were reported in $44.6 \%$ of children diagnosed with autism [28]. Epilepsy is observed in up to $33 \%$ of individuals with autism [106].

The phenotypic heterogeneity is a major obstacle in all areas of autism research [83] and may be the result of a contribution of non-overlapping gene effects. The genetic fractionation of social impairment, communication difficulties and rigid and repetitive behaviors suggests that different features of autism are caused by different genes associated with different brain regions and are related to different cognitive impairments and functional abnormalities [48].

In spite of the broad spectrum of clinical manifestations and striking inter-individual differences, studies of thousands of children have resulted in establishing the clinical diagnostic criteria of pervasive developmental disorder [1]; however, corresponding neuropathological diagnostic criteria do not exist. One of the reasons for the disproportionate progress in clinical and neuropathological studies is the limited tissue resources available for postmortem studies. Between 1980 and 2003, only 58 brains of individuals with autism were examined [85]. Due to the diversity of research aims, of protocols for tissue preservation and of methods of sampling and examination, and the small number of brains examined in an individual project, the pattern of neuropathological changes emerging from these studies remains incomplete and inconsistent.

The hypothesis that autism is associated with neuropathological changes was explored in the first reports published between 1980 and 1993 [7, 21, 22, 27, 42, 50, 51, $82,90]$. Since then, implementation of broader diagnostic terms such as Autism Spectrum Disorder (ASD), examination of larger cohorts, applications of stereology, and functional and structural magnetic resonance imaging (MRI) have resulted in the detection of several major types of pathology, most likely contributing to the clinical phenotype. An emerging concept of autism-related brain pathology integrates evidence of (a) abnormal acceleration of brain growth in early childhood [89], (b) minicolumn pathology [13, 14], (c) curtailed neuronal development [7, 108] and brain structure-specific delays of neuronal growth [111] with indications of abnormalities in brain cytoarchitecture [4, 7], metabolic modifications with abnormal amyloid protein precursor (APP) processing [5, 101], enhanced oxidative stress [17] and enhanced turnover of cell organelles with pigment accumulation and glial activation [68].

In spite of the conceptual limitations, "localizing" models are still the main approach to the identification of pathological changes as a component of the networks' structural and functional abnormalities [81]. We hypothesize that dysregulation of neurogenesis, neuronal migration and maturation is also reflected in qualitative, focal, developmental alterations of brain microarchitecture. The aim of this study is to detect the pattern of focal, qualitative, developmental defects in autism brain, including their type, topography and severity, and to identify the structures and brain regions that are prone to developmental alterations in autism.

\section{Materials and methods}

The autistic cohort study consisted of 13 subjects (462 years of age), including 9 males $(69 \%)$ and 4 females (31\%), while the control cohort consisted of 14 subjects (464 years of age), including 9 males and 5 females (Table 1).

Clinical and genetic characteristics of the autistic subjects

The source of our clinical data was the medical records of the autistic subjects, which consisted of psychological, behavioral, neurological and psychiatric evaluation reports. All of the records were obtained after the subjects' deaths. The Autism Diagnostic Interview-Revised (ADI-R) was administered to each donor family as a standardized assessment tool in order to confirm the diagnosis on a postmortem basis. Inclusion of the subject in this study was based on a summary of scores of four domains: 
Table 1 Material examined

\begin{tabular}{|c|c|c|c|c|c|c|c|c|}
\hline$\#$ & Group & Brain bank \# & Sex & Age (years) & Cause of death & PMI (h) & $\mathrm{H}$ & Brain weight $(\mathrm{g})$ \\
\hline 1 & A & IBR425-02 & M & 4 & Drowning & 30 & $\mathrm{R}$ & 1,280 \\
\hline 2 & A & UMB-1627 & $\mathrm{F}$ & 5 & Traumatic multiple injuries & 13.2 & $\mathrm{R}$ & 1,390 \\
\hline 3 & A & B-6403 & M & 7 & Drowning & 25 & $\mathrm{R}$ & 1,610 \\
\hline 4 & A & B-5666 & M & 8 & Rhabdomyosarcoma & 22.2 & $\mathrm{R}$ & 1,570 \\
\hline 5 & A & B-5342 & $\mathrm{F}$ & 11 & Seizure-related drowning & 12.9 & $\mathrm{~L}$ & 1,460 \\
\hline 6 & A & B-5535 & M & 13 & Seizure-related & 8 & $\mathrm{~L}$ & 1,470 \\
\hline 7 & A & B-6115 & $\mathrm{F}$ & 17 & Cardiac arrest related to cardiomyopathy & 25 & $\mathrm{~L}$ & 1,580 \\
\hline 8 & A & UMB-1638 & $\mathrm{F}$ & 21 & Seizure-related respiratory failure & 50 & $\mathrm{R}$ & 1,108 \\
\hline 9 & A & B-6337 & M & 22 & Seizure-related & 25 & $\mathrm{R}$ & 1,375 \\
\hline 10 & A & IBR93-01 & M & 23 & Status epilepticus-related respiratory failure & 14 & $\mathrm{R}$ & 1,610 \\
\hline 11 & A & B-6212 & M & 36 & Cardiac arrest & 24 & $\mathrm{R}$ & 1,480 \\
\hline 12 & A & B-6276 & M & 56 & Cardiac arrest & 3.35 & $\mathrm{R}$ & 1,570 \\
\hline 13 & A & B-7090 & M & 60 & Pancreatic cancer & 26.5 & $\mathrm{R}$ & 1,210 \\
\hline 1 & $\mathrm{C}$ & B-6736 & $\mathrm{F}$ & 4 & Acute bronchopneumonia & 17 & $\mathrm{R}$ & 1,530 \\
\hline 2 & $\mathrm{C}$ & UMB-1499 & $\mathrm{F}$ & 4 & Lymphocytic myocarditis & 21 & $\mathrm{R}$ & 1,222 \\
\hline 3 & $\mathrm{C}$ & UMB-4898 & M & 7 & Drowning & 12 & $\mathrm{R}$ & 1,240 \\
\hline 4 & $\mathrm{C}$ & UMB-1708 & $\mathrm{F}$ & 8 & Traumatic multiple injuries & 20 & $\mathrm{R}$ & 1,222 \\
\hline 5 & $\mathrm{C}$ & BTB-3638 & M & 14 & Electrocution & 20 & $\mathrm{R}$ & 1,464 \\
\hline 6 & $\mathrm{C}$ & UMB-1843 & $\mathrm{F}$ & 15 & Traumatic multiple injuries & 9 & $\mathrm{R}$ & 1,250 \\
\hline 7 & $\mathrm{C}$ & UMB-1846 & $\mathrm{F}$ & 20 & Traumatic multiple injuries & 9 & $\mathrm{R}$ & 1,340 \\
\hline 8 & $\mathrm{C}$ & UMB-1646 & M & 23 & Ruptured spleen & 6 & $\mathrm{R}$ & 1,520 \\
\hline 9 & $\mathrm{C}$ & UMB-4543 & M & 29 & Traumatic multiple injuries & 13 & $\mathrm{R}$ & 1,514 \\
\hline 10 & $\mathrm{C}$ & UMB-1576 & M & 32 & Traumatic compressional asphyxia & 24 & $\mathrm{R}$ & 1,364 \\
\hline 11 & $\mathrm{C}$ & BTB-3899 & M & 48 & Atherosclerotic heart disease & 24 & $\mathrm{~L}$ & 1,412 \\
\hline 12 & $\mathrm{C}$ & IBR252-02 & M & 51 & Myocardial infarct & 18 & $\mathrm{~L}$ & 1,450 \\
\hline 13 & $\mathrm{C}$ & BTB-3983 & M & 52 & Heart atherosclerosis & 13 & $\mathrm{R}$ & 1,430 \\
\hline 14 & $\mathrm{C}$ & B-6874 & M & 64 & Cardiac arrest & 28 & $\mathrm{R}$ & 1,250 \\
\hline
\end{tabular}

$P M I$ postmortem interval, $H$ hemisphere, $R$ right, $L$ left

(a) qualitative abnormalities in reciprocal social interaction; (b) qualitative abnormalities in verbal and nonverbal communication; (c) restricted, repetitive and stereotyped patterns of behavior; and (d) abnormality of development evident at or before 36 months [69]. All 13 autistic subjects met ADI-R criteria for autism. For some subjects, the intellectual evaluation was available and was based on the Wechsler Intelligence Scale for Children III and the Woodcock-Johnson Tests of Achievement-Revised (Table 2). Eight subjects were diagnosed with intellectual disability, usually in the range from mild to severe $(61 \%)$. Six of 13 autistic subjects had seizures (46\%). In five cases, the age of onset of seizures was from 14 months to 5 years of age. A 23-year-old autistic male had only one seizure, which was reported as the cause of his death. In one child, an abnormal EEG was detected, but without seizures.

Several forms of challenging behaviors and behavioral disorders were noted, including self-injurious behavior (six cases, 46\%), aggression (four cases, 31\%), hyperactivity (three cases, 23\%), obsessive compulsive disorder (two cases, 12\%) and depression and mania (a single case of each).

For three of the 13 autistic subjects, the list of highconfidence copy number variations identified both by quantiSNAP and Partek HMM computational algorithm was posted on the ATP portal by Drs. Steve Scherer and Richard Wintle from The Center for Applied Genomics, Toronto. The copy number variations detected in the three autistic subjects do not differ from those commonly observed [75], except for the loss of 25,505 kb within Neuropeptide S Receptor 1 (NPSR1) gene at 7p15-p14 detected in a 22-year-old autistic male (B-6337). NPSR1 has not been linked to autism in the genomic reports [103, 112]; however, an association of NPSR1 copy number variation with allergies has been reported [11] that might be linked to the patient's history of allergies.

Originally, 38 brains, including 20 brains of autistic and 18 brains of control subjects, were assigned to this project. However, application of the clinical and neuropathological 
Table 2 Behavioral and neurological signs, and the type and topography of developmental abnormalities

\begin{tabular}{lllll}
\hline Brain bank \# & $\begin{array}{l}\text { Psychiatric disorders and } \\
\text { neurological symptoms }\end{array}$ & $\begin{array}{l}\text { Mental } \\
\text { retardation } \\
\text { (MR) }\end{array}$ & $\begin{array}{l}\text { Seizures age } \\
\text { of onset }\end{array}$ & $\begin{array}{l}\text { Type and topography of developmental } \\
\text { abnormalities }\end{array}$
\end{tabular}

IBR425-02 Hyperactivity. Tantrums. Self-injurious behavior

B-6403 $-$

B-5666

B-5342

Pervasive developmental disorder. Hyperlexia

B-5535

$$
\begin{aligned}
& \text { Hyperactivity. Self- } \\
& \text { injurious behavior } \\
& \text { including head-banging }
\end{aligned}
$$
Moderate to severe MR

Abnormal EEG; no seizures

\section{Mild MR}

4.5 months

14 months

\section{2 years}

UMB-1627 Aggression

\section{No changes}

Focal neuronal heterotopia in white matter of the anterior cingulate gyrus

Subependymal nodular dysplasia in the wall of the occipital horn of the lateral ventricle. Two periventricular nodular heterotopias ( 2 and $4 \mathrm{~mm}$ in diameter) near the frontal horn of the lateral ventricle. Tuber-like expansion of the tail of caudate nucleus into the lumen of the ventricle. Flocculonodular dysplasia

Cortical dysplasia in the middle and inferior temporal gyri with focal dyslamination, clustering of dystrophic neurons and severe local neuronal deficits. Several focal dysplastic changes within CA. Flocculonodular dysplasia affecting almost entire lobe

Focal cortical dysplasia. Dysplasia of the granule layer of the dentate gyrus. Subcortical heterotopia in the inferior frontal gyrus. Heterotopia in vermis and in cerebellar white matter

Thickening of the subependymal cell layer. Focal dysplasia within CA1 pyramidal layer with neuronal deficit, abnormal neuron morphology and spatial orientation. Multifocal dysplasia of the dentate gyrus with distortion of the shape of granule and molecular cell layers. Focal dysplasia within vermis

Flocculonodular dysplasia affecting the majority of lobe volume. Cortical angioma

Focal dysplasia within CA1 with diffuse neuronal deficit but without glial activation

Minor focal flocculonodular dysplasia

Obsessive compulsive disorder. Depression, aggression, and anxiety

B-6276

Aggression and selfinjurious behavior, anxiety and agitation

B-7090

Disturbed movement coordination (walking like drunk)
Severe MR 23 years

Severe MR

Moderate MR 5 years

MR

Moderate MR

MR

3 years
Focal dysplasia within islands in the entorhinal cortex. Pineal gland cysts

Several areas of focal cortical dysplasia within frontal cortex and insula with local loss of vertical and horizontal organization. Merger of ventral portion of the claustrum with insula. Flocculonodular dysplasia

Focal dysplasia within CA1 sector with focal neuronal deficit. Heterotopia within stratum oriens. Flocculonodular dysplasia affecting approximately $70 \%$ of the lobe

Three focal dysplasias in the frontal cortex. Dysplasia of layers 1-3 in the entorhinal cortex with missing numerous islands of the stellate neurons. Severe hypoplasia of cerebellar lobes 14. Reduced convolutions within dentate nucleus

Developmental abnormalities in brains of autistic subjects 
exclusion criteria reduced the size of the cohort to 27 brains. Based on the results of the ADI-R, two cases were excluded, including one case diagnosed with atypical autism, and one that did not meet ADI-R criteria. Based on postmortem evaluation, five more autistic cases were excluded: one due to severe postmortem autolytic changes, three due to severe global hypoxic encephalopathy related to the mechanism of death, and one due to multiple microinfarcts. Moreover, four brains of control subjects were disqualified due to severe postmortem autolysis. In all these brains, neuronal loss, changes of neuronal size and shape, and gliosis were so severe that they masked and distorted the qualitative and quantitative characteristics of the developmental alterations associated with autism.

\section{Brain tissue preservation}

Brains of 13 autistic and 14 age-matched control subjects were examined by postmortem MRI and neuropathologically. The postmortem interval (PMI) varied, ranging from 6 to $27.8 \mathrm{~h}$ in the control group (16 h on average; SD $6 \mathrm{~h}$ ) and from 8 to $30 \mathrm{~h}$ in the autistic group (20 h on average; SD $12 \mathrm{~h}$ ). The median PMI was $15 \mathrm{~h}$.

The brain hemispheres were removed using standard techniques, exercising extra care to avoid damaging the brain tissue. The brain was weighed in the fresh state. The fresh brain was sagittally cut through the corpus callosum and brainstem. Half of the brain was fixed in $10 \%$ buffered formalin. Following at least 3 weeks of fixation, the brain hemisphere was scanned using MRI. The aim of the MRI application was to determine the type of developmental changes detectable by MRI and to microscopically characterize MRI findings. All brains within this project were scanned (L.A.S.L.) using a standardized protocol (established and implemented for this and for other postmortem MRI studies by L.A.S.L. and M.L.). MRI scans were acquired on a $1.5 \mathrm{~T}$ GE Signa Imager (General Electric, Milwaukee, USA). The research scan consisted of a 124slice T1-weighted fast gradient echo acquired in a coronal orientation perpendicular to the long axis of the hippocampus with a 1.5-mm slice thickness, which encompassed the entire brain hemisphere without gaps or wrap artifacts $(\mathrm{FOV}=25 \mathrm{~cm} ; \mathrm{NEX}=1 ;$ matrix $=256 \times 192 ; \mathrm{TR}=$ $35 \mathrm{~ms} ; \mathrm{FA}=60^{\circ}$ ). All file names were assigned sequential code numbers, and demographic information was removed from image headers [9]. MRI scans were first screened in a diagnosis-blind manner, and the brains with abnormalities were re-evaluated by both radiologists and neuropathologists to determine the topography, type, and size of lesions detected with both methods.

The brain hemisphere was fixed with $10 \%$ buffered formalin. Formalin was washed out from the tissue during an overnight tap water rinsing. Brains were dehydrated using a series of increasing ethyl alcohol concentrations (50\% ethanol 3 days; $70 \%$ ethanol 4 days; $80 \%$ ethanol 3 days; $95 \%$ ethanol 4 days). The brain hemisphere was embedded in $8 \%$ celloidin [53]. During hardening, celloidin blocks were exposed to chloroform vapors for approximately 2.5 weeks, and celloidin blocks were then stored in $70 \%$ ethanol. For sectioning, the block was attached to the block holder with $10-15 \mathrm{ml}$ of $8 \%$ celloidin. To fasten adhesion of the block to the holder, the block with the holder attached was immersed in $70 \%$ ethanol overnight. Serial 200- $\mu$ m-thick sections were separated with filter paper and stored in $70 \%$ ethanol. For the four control and four brains of autistic subjects, alternative series of 200- and 50- $\mu \mathrm{m}$-thick sections were preserved. To ensure the same probability of detection of changes in each case, every 200- $\mu \mathrm{m}$-thick section, with a distance $1.2 \mathrm{~mm}$, was used in this project. Sections were washed in water for 2-3 h, stained with cresyl violet $(\mathrm{CV})$ and mounted with Acrytol.

One neuropathologist (I.K.) examined, in a blind-todiagnosis fashion, on average 120 hemispheric CV-stained sections per case with a $1.2-\mathrm{mm}$ distance between sections. Two-step screening included examination at low magnification $(28 \times)$ using Zeiss DL2 Documator and microscopic examination using objective lenses from $5 \times$ to $100 \times$. Two other neuropathologists (T.W. and J.W.) examined all histological slides for which pathology was detected during the primary screening. The defects of neurogenesis, neuronal migration, and dysplastic changes that they detected were summarized in this report.

Tissue acquisition for this program project is based on individual tissue transfer agreements between the program project's principal investigator and several tissue banks: (a) the NICHD Brain and Tissue Bank for Developmental Disorders at the University of Maryland, (b) the Harvard Brain Tissue Resource Center and (c) the Brain Bank for Developmental Disabilities and Aging of the NYS Institute for Basic Research in Developmental Disabilities. Each brain hemisphere number given by the institution that received the donation was used as the only identifier of clinical records and tissue samples. Brain Bank identification of tissue samples is listed in Tables 1 and 2 to keep non-overlapping records of results of examination of brains in different projects and research groups. The Institutional Review Board of the New York State Institute for Basic Research in Developmental Disabilities approved the methods applied in this study.

\section{Results}

Neuropathological evaluation of serial coronal hemispheric sections from the cerebral and cerebellar hemispheres of 
Fig. 1 Nodules in the wall of the lateral ventricle detected in postmortem MRI (a) in the brain of a 7-year-old male diagnosed with autism (B-6403) revealed features of

subependymal nodular dysplasia (SND; $\mathbf{b})$ in examination of $\mathrm{CV}$ stained sections. c Numerous large and small nodules (arrow) dispersed within subependymal cell layer. They contained a few pyramidal-like neurons (d) and numerous poorly differentiated cells (e). Tuber-like expansion of the caudate nucleus (arrow) into the ventricle lumen is shown in MRI (f) and in $\mathrm{CV}$ stained section (g). g A thick subependymal cell layer above and below (two arrows) the caudate nucleus $(C N)$, and the absence of matrix in the tuberlike area. Under ependymal $(E)$ cap of the caudate nucleus $(C N)$ tuber-like expansion, small poorly differentiated neurons are present (h)
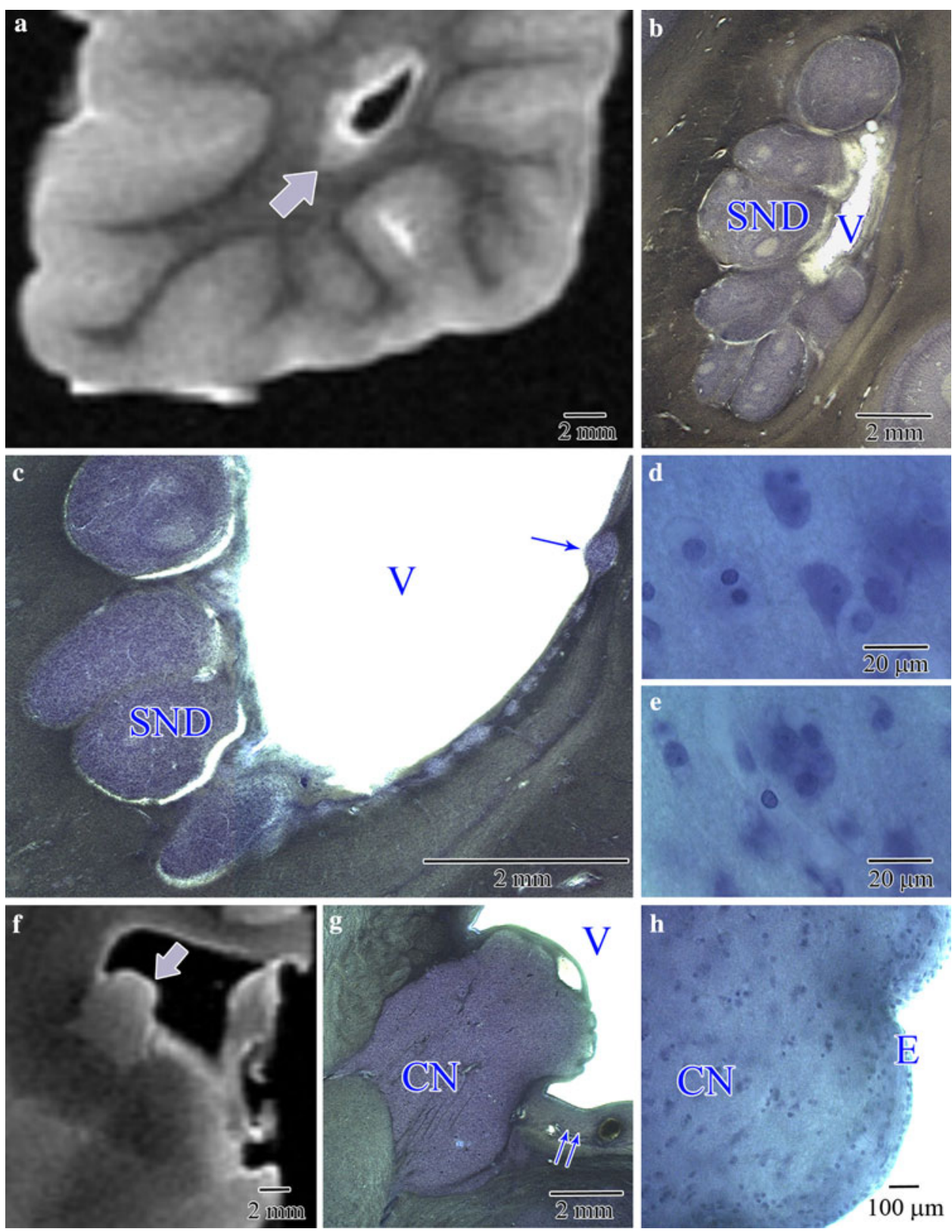

13 autistic and 14 control subjects revealed more details characterizing the topography and severity of changes than did standard sampling of brains for routine neuropathological evaluation. A broad range of changes was found. Developmental abnormalities included subependymal nodular dysplasia, heterotopia and very common dysplastic changes within the neo- and archicortex, hippocampus and cerebellum in 12 of 13 examined brains of the autistic subjects (92\%) (Table 2). The general result of these developmental defects was a multifocal disorganization of gray and white matter. The developmental pathology observed in control brains was limited to one cerebellar dysplasia.
Alterations of the subependymal cell layer and subependymal nodular dysplasia

In two autistic subjects, there was a several-fold local increase in the thickness of the subependymal cell layer. Numerous subependymal nodules were found within a pathologically thickened subependymal cell layer, in the wall of the occipital horn of the lateral ventricle of a 7-year-old male, which reflects a subependymal nodular dysplasia (Fig. 1a-e). Nodules occupied $13.3 \mathrm{~mm}$ of the caudal portion of the occipital horn of the lateral ventricle. The diameter of round/oval nodules varied in size from 285 to $3,310 \mu \mathrm{m}$. While the smallest nodules were dispersed 
within the subependymal cell layer, the large nodules expanded partially into the white matter, and partially into the lumen of the ventricles and were detectable on MRI (Fig. 1a) and CV-stained histological sections (Fig. 1b, c). The effect was narrowing of the ventricle and the tuberous appearance of the ventricular wall. There were large tubers that contained dysplastic neurons with a partially modified morphology of pyramidal, multipolar or bipolar large neurons (Fig. 1d) and irregularly shaped medium and small neurons. Neurons in the small nodules were small and poorly differentiated (Fig. 1e). In the large nodules, several hypocellular areas were observed. The nodules were free of oval or polygonal giant cells or ballooned glial cells, as well as signs of calcification.

In the brain with the subependymal nodular dysplasia, an abnormal tuberous expansion of the caudate nucleus was detected on MRI (Fig. 1f) and in histological sections (Fig. 1g, h). Only the ependyma separated the tuber-like expansion of the caudate from the ventricle lumen. The very thick subependymal cell layer that was present close to the caudate was substituted by loosely arranged and poorly differentiated neurons in the affected area.

\section{Heterotopia}

Heterotopias were found in the brains of four autistic subjects and no control subjects. The topography of the lesions was different in each case. Subcortical heterotopias were detected in the white matter of the anterior cingulate gyrus of a 5-year-old (Fig. 2a, b) and in the inferior frontal gyrus in an 11-year-old subject. Periventricular heterotopias were detected near the wall of lateral ventricle in 7-year old subject (Fig. 2c, d). A single heterotopia was noted in the stratum oriens of the hippocampus. In the cerebellum of the 11-year-old subject, heterotopias were detected in the vermis and the cerebellar white matter close to the dentate nucleus (Fig. $2 \mathrm{f}-\mathrm{h}$ ). These defects of migration were observed in two brains as a single aggregate of gray matter, in one brain as two aggregates and in one brain as three lesions measuring from 1 to $3 \mathrm{~mm}$ in diameter. Subcortical and periventricular heterotopias comprised poorly differentiated oval or multipolar neurons without spatial orientation (Fig. 2a) or had a distorted laminar organization (Fig. 2e). Cerebellar heterotopias had a distorted morphology of the granule and molecular layers with a few dispersed Purkinje cells (Fig. $2 \mathrm{~g}$, h).

Dysplasia within neocortex and archicortex, hippocampus and cerebellum

The multifocal neocortical dysplasia detected in four brains of autistic subjects (31\%) was associated with a local loss of vertical and horizontal organization of the neocortex, formation of abnormal layers, loss of orientation of neurons (Fig. 3a, b) and thickening of the affected portion of the cortical ribbon. A focal dysplasia in the entorhinal cortex, observed mainly in the second layer with a local absence of islands and/or reduced number of neurons, was found in the 23-year-old and the 60-year-old autistic subjects (15\%) (Fig. 3c, d). A lack of giant multinuclear neurons and large, ballooned glial cells typical of focal cortical dysplasia indicated that the observed developmental changes in neocortex and archicortex reflect a more subtle cortical malformation, classified usually as focal cortical microdysgenesis.

Two types of changes were observed in the dentate gyrus. An abnormal migration of granule neurons into the molecular layer resulted in the formation of an additional fragmentary granule cell layer (Fig. 3e). In other areas, granule cells formed irregular circles and loops (Fig. 3f).

In the CA1 sector of a 13-year-old male, several areas of dysplastic changes with a significant deficit of pyramidal neurons without gliosis were found (Fig. 3g). In affected areas, the size and shape of neurons varied over a wide range. Pyramidal neurons were very rare, whereas small irregular or oval-shaped, poorly differentiated neurons prevailed (Fig. 3h). In the dysplastic area in the CA1 sector of the 56-year-old autistic subject, an opposite trend was present, with thickening of the pyramidal layer and an increased packing of dysplastic neurons (not shown).

The most common developmental abnormality within the cerebellum was dysplasia, which was detected in seven autistic subjects (54\%) and in the cerebellum of one control subject.

Flocculonodular dysplasia (Fig. 4a, b), usually affecting the entire nodule, was found in the cerebellum in six autistic subjects (46\%). In the dysplastic areas, a thin granule layer formed the labyrinth, which was mixed with irregular islands of the molecular layer. Clusters of granule cells and a few Purkinje cells were dispersed within the distorted molecular layer. The only developmental abnormality detected in the control group was flocculonodular dysplasia in the cerebellum of the 51-year-old control subject (not shown). Local cortical dysplasia was also detected within the vermis of the 13-year-old autistic male. In the affected area, the cytoarchitecture of the molecular and granule layers and the Purkinje cells was completely disorganized (Fig. 4c, d).

In the cerebellum of the 60-year-old autistic male, severe hypoplasia affected lobes 1-4 (Fig. 4e). The thickness of the molecular and granular layer was decreased by almost $50 \%$ in comparison to that of the non-affected areas (Fig. 4e, f). The number of Purkinje cells was significantly reduced in the hypoplastic area. Hypoplastic changes within the portion of cerebellar cortex were observed, 

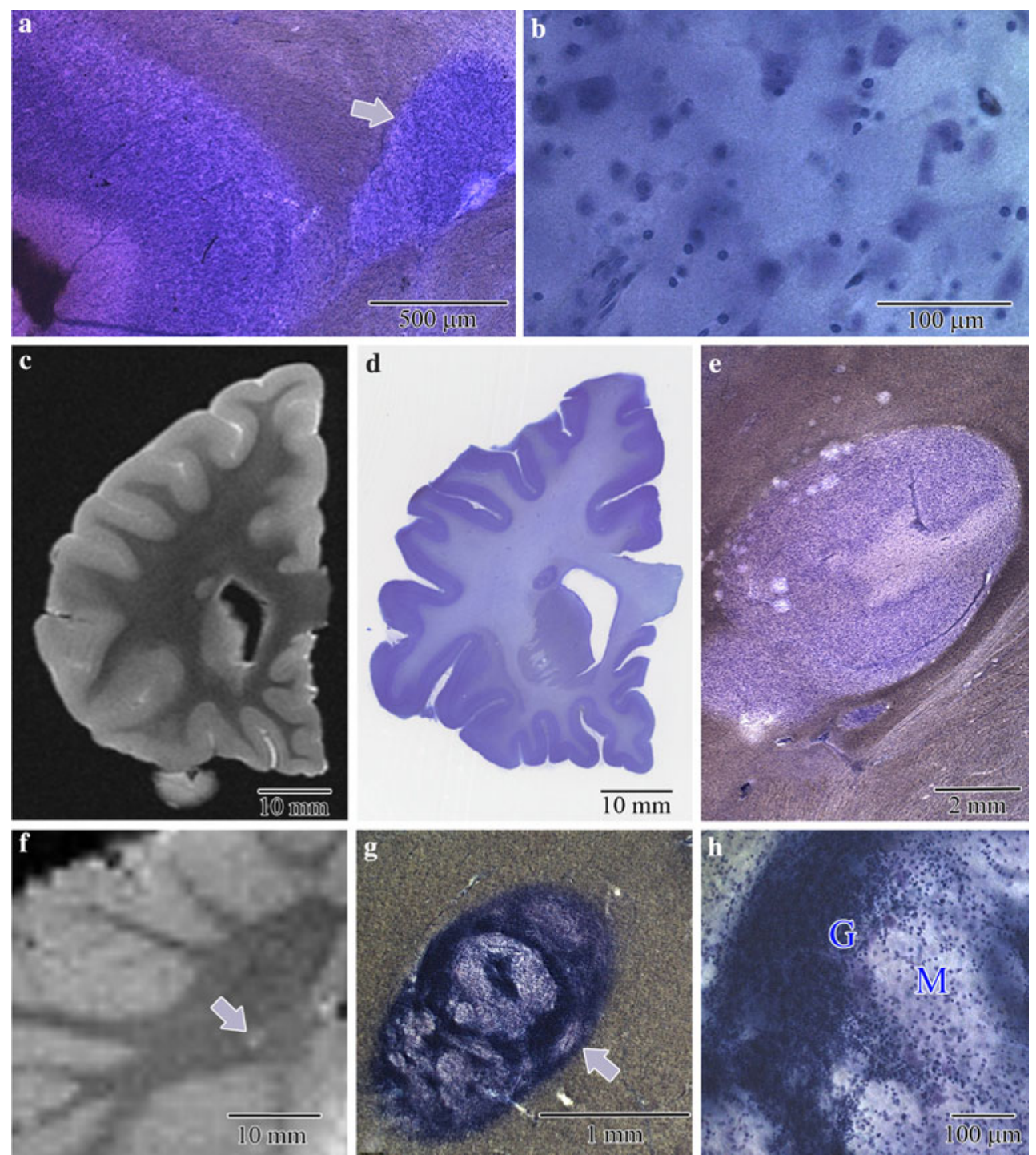

Fig. 2 Large subcortical heterotopia within anterior cingulate gyrus in a 5-year-old autistic child (UMB-1627) (a) contained dysplastic neurons without spatial orientation (b). Periventricular heterotopia near the frontal horn of the lateral ventricle (c MRI, d, e CV-stained section) shows a structure resembling molecular, granule and

together with a significantly reduced convolution of the dentate nucleus (Fig. 4g).

\section{Discussion}

This neuropathological study revealed a broad spectrum of focal developmental abnormalities and pre- and perinatally acquired lesions in $92 \%$ of the brains of autistic subjects and striking inter-individual differences in the type and topography of changes. Evidence that different features of autism are caused by different genes associated with different brain regions [48] suggests a link between regional pyramidal layers in a 7-year-old autistic subject (B-6403). MRI (f), low (g) and large (h) magnification of heterotopia (arrow) with dysplastic granule $(G)$ and molecular layer $(M)$ detected within cerebellar white matter in an 11-year-old autistic subject (B-5342)

developmental alterations in the brain and different components of the autistic phenotype.

\section{Altered neurogenesis in autism}

Increased brain mass in autistic children and some autistic adults [89], increase in the numerical density of neurons $[13,14]$, reduced size of neurons [7] and brain structurespecific delay of neuronal growth [111] indicate alterations in neuronal and brain growth in autistic individuals. The subventricular zone of the lateral ventricles [26] and the dentate gyrus [33] are active sites of neurogenesis in adult humans. Several of our findings support the hypothesis of 

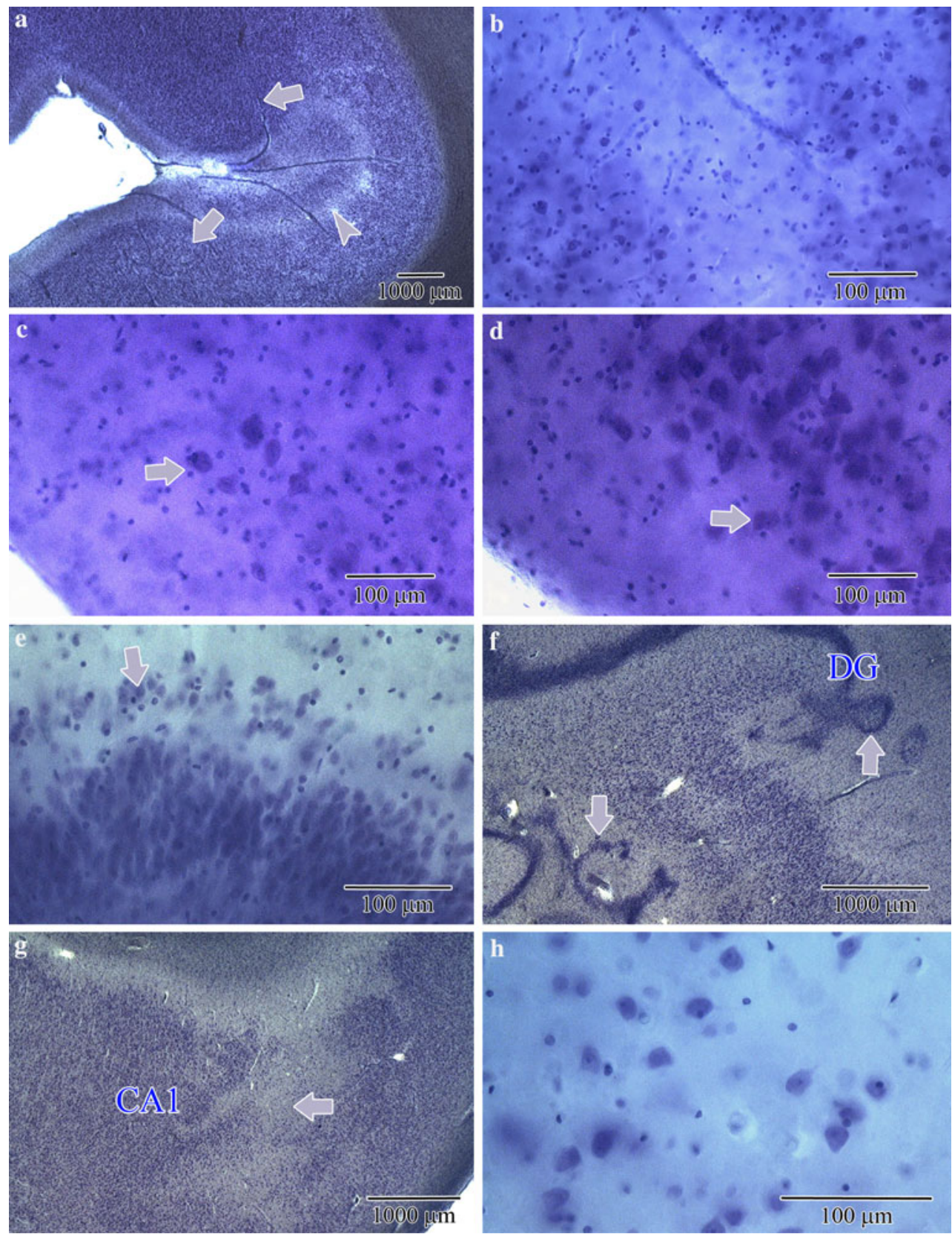

Fig. 3 Dysplastic changes within neocortex $(\mathbf{a}, \mathbf{b})$, entorhinal cortex (c, d), dentate gyrus (e, f) and the cornu Ammonis (g, h). Focal dysplasia in frontal cortex with loss of vertical and horizontal cytoarchitecture (two arrows) and abnormal (arrowhead) laminar organization (a). Dysplastic neurons within affected area (B-6212) (b). Microdysgenesis within the entorhinal cortex with deficit of stellate neurons in the islands (c) and normal morphology of islands in adjacent cortex (d) in 60-year-old autistic subject (B-7090).

Microdysgenesis of the dentate gyrus with dispersion of granule cells within the molecular layer (e, arrow) and distortion of the granule cell layer shape (f, arrows) in 13-year-old autistic male (B-5535). CA1 sector microdysgenesis with local deficit of pyramidal neurons (g, arrow) without markers of gliosis but with signs of poor differentiation of dysplastic abnormally arranged neurons (h) in 13-year-old autistic subject (B-5535)

altered neurogenesis in autistic subjects. The increased thickness of the subependymal cell layer, subependymal nodular dysplasia, abnormal growth of the dentate nucleus and dysplasia of the granule layer in the dentate gyrus, detected in this study, appear to be signs of abnormal neurogenesis in the brains of three autistic subjects.

Subependymal nodules were reported in approximately $80 \%$ of patients with tuberous sclerosis, a disorder that is highly associated with epilepsy, autism and mental retardation [73]. Tuberous sclerosis nodules were detected in one fetus [12], suggesting that fetal development of subependymal nodules can lead to the early onset of epilepsy 
Fig. 4 Flocculonodular dysplasia in cerebellum of 56-year-old autistic subject (B-6276) (a) with thin irregular granule $(G)$ and molecular $(M)$ layer. b Dysplastic granule layer $(G)$, ectopic granule cells (arrow) in the molecular layer, and loosely dispersed Purkinje cells $(P)$ (B-6276). Cortical dysplasia within vermis of 13year-old autistic male (c) with dysplastic granule neurons mixed with heterotopic (arrow) large cells (d) (B-5535). e Severe hypoplasia of cerebellar lobe 3 and unmodified lobe 6 (f), respectively, within the cerebellum of a 60 -year-old autistic male (B-7090). In the affected region, the thickness of the hypoplastic molecular and granule cell layer was reduced by about $50 \%$. Almost half of the dentate nucleus $(D N)$ was less convoluted than the unaffected part (g)
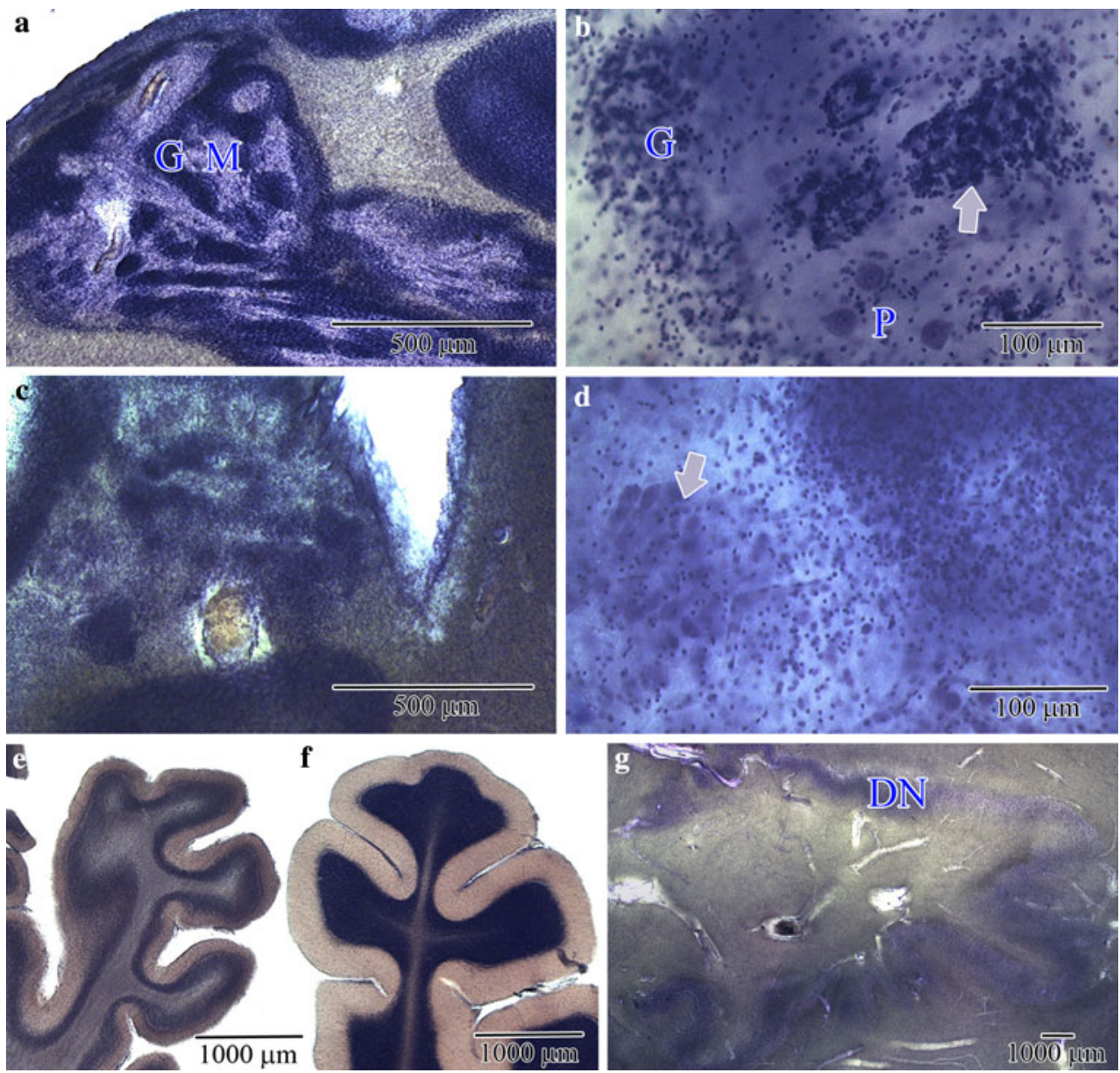

that was diagnosed at the age of 14 months in a neuropathologically examined autistic male. The subependymal nodules detected in this autistic male's brain are partially similar to tubers seen in subjects diagnosed with tuberous sclerosis [24]. The cause of subependymal nodular dysplasia in the examined subject is unknown. In the reported subjects, bilateral periventricular nodules are linked to mutations of the filamin A (FLNA) gene located on chromosome $\mathrm{Xp} 28$. Filamin $\mathrm{A}$ is an actin-crosslinking protein that is essential for cell locomotion [16], and nodule formation might be related to a defect in cell migration. The presence of miniature nodules that were built of poorly differentiated small neurons within the subependymal cell layer and an increase in nodular size with signs of growth and differentiation of neurons suggests that neurogenesis, differentiation and maturation of neurons were in progress within the subependymal germinal matrix of the 7-year-old autistic child. This interpretation of subependymal nodule genesis is consistent with lineage studies demonstrating that cells in nodules express cellular markers that are typical for progenitors derived from the subventricular germinal zone $[35,67]$. However, in contrast to the subependymal nodules seen in subjects with tuberous sclerosis, in the examined autistic subject, the nodules seen were small (from 258 to $3,310 \mu \mathrm{m}$ in diameter), and did not have the characteristic ovoid or polygonal giant cells, 80$150 \mu \mathrm{m}$ in diameter, giant cells with multiple and peripherally displaced nuclei [25], or balloon cells, which are considered the sine qua non histopathological features of the cortical tubers and subependymal nodules observed in tuberous sclerosis [73].

The enlarged caudate nucleus detected in the brain of the 7-year-old autistic subject is consistent with MRI reports documenting an increased volume of basal ganglia, including the caudate, in autism [54, 55, 66, 99]. A disproportionate increase of the caudate nucleus volume [66] suggests that in brains of some autistic individuals, extended neurogenesis within the subependymal cell layer may contribute to abnormal growth of the caudate nucleus. A similar process has been observed in the brains of people with Huntington disease, showing enhanced neurogenesis in the subependymal layer and suggesting renewal of the neuronal population in a degenerating caudate nucleus [26]. The caudate nucleus is a part of the fronto-striatal network involved in several functional domains that are impaired in autism, including lower order repetitive motor 
behavior; intense circumscribed patterns of interests and higher order rituals and compulsions [41], and defects in cognitive functions [19, 109], planning and problemsolving skills [78, 98], short- and long-term memory [40] and learning [88].

\section{Defective migration in autism}

Heterotopia is a sign of altered migration leading to an abnormal distribution of gray matter nodular masses with disorganized or rudimentary lamination within the periventricular area (periventricular heterotopia) or subcortical white matter (subcortical heterotopia) [2]. In the examined cohorts, heterotopias were detected in the brains of four autistic subjects and in the brain of one control subject. Heterotopias are associated with mutations in the filamin 1 gene (FLNA1) [39, 46] and the chromosome X-linked DCX gene that codes for doublecortin, a protein expressed during brain development in migrating neurons, and in the cortical plate $[29,44,45]$, which is involved in the formation of the microtubules necessary for neuronal migration [15]. Periventricular nodular heterotopia has been reported to be associated with pharmaco-resistant seizures in $80-90 \%$ of patients [31]. In the examined cohort, two periventricular heterotopias were detected in the brain of a child with subependymal nodular dysplasia and seizures diagnosed at 14 months of age (B-6403). Early onset epilepsy, diagnosed at the age of 4.5 months, might be related to the multiple heterotopias found within the frontal inferior gyrus, vermis and cerebellar white matter, coexisting with a focal cortical dysplasia and dentate gyrus dysplasia (B-5342).

Cortical, hippocampal and cerebellar dysplasia in autism

The most common form of developmental changes detected in the examined brains was focal dysplasia, which was observed in $11(85 \%)$ of the autistic subjects. The morphology of focal dysplasias appears to reflect signs of abnormal migration, neuronal immaturity and altered cell arrangement, resulting in focal distortion of cytoarchitecture. In spite of similarities, the dysplastic changes in the neocortex and archicortex, dentate gyrus and cornu Ammonis and cerebellum also reveal a brain structurespecific pattern of dysplastic changes in autism.

Dysplasias encompass a spectrum of changes ranging from a mild form of cortical disruption, without cellular abnormalities, to the most severe form with cortical dyslamination, with abnormal morphology of neurons and astrocytes [93, 96, 107]. Focal cortical dysplasias with giant neurons and balloon cells [107, 113] are histopathologically similar to tubers containing giant cells in tuberous sclerosis complex [25, 73], suggesting a common pathogenic basis [113]. However, activation of the mammalian target of rapamycin (mTOR) pathway observed in the tuberous sclerosis complex is not present in focal cortical dysplasia $[8,80]$. The giant neurons and ballooned cells, which are histopathological features of tuberous sclerosis and focal cortical dysplasia, were absent both in the subependymal nodules and in the focal cortical dysplasia observed in the examined autistic cohort. These findings suggest that in spite of similarities, the pathomechanisms of developmental alterations are different in the examined autistic subjects than those in tuberous sclerosis heterotopias or focal cortical dysplasia. The development of the giant neuron- and balloon cell-free dysplasias observed in the autistic subjects might be related to differences in cause and/or mechanism. The detection of changes similar to focal cortical dysplasia in association with prenatal ischemia [65] or in shaken infant syndrome [74] may support these speculations.

Ectopias and dysplastic changes were reported in the brains of autistic subjects, by several groups [4, 62-64, 91]. Bailey et al. [4] detected olivary dysplasia in the brain of three of the five autistic subjects, and ectopic neurons related to the olivary complex in two cases. Moreover, in the brains of four autistic subjects, cortical dysgenesis was found. In the brains of the autistic subjects, a strikingly consistent finding was cingulate cortex disordered lamination $[62-64,100]$. A recent study of the cingulate cortex of nine autistic subjects revealed a developmental malformation with irregular lamination in three cases, and an increased number of neurons within the subcortical white matter in two [100]. Simms et al. [100] suggest that the excessive number of neurons in the subcortical white matter reflects the lack of proper resolution of the transient zone in the developing brain of autistic subjects. Studies by Fatemi et al. [37, 38] link the migration and lamination defects to a striking reduction of reelin (by 40\%) and Bcl-2 (by 34-51\%) in the brains of autistic subjects. Our studies along with others' suggest that in the majority of autistic subjects, heterotopias and dysplastic changes are the local sign of general developmental defects of migration with a broad spectrum of topographic, morphological, and functional outcomes.

In the examined brains of autistic subjects, signs of neuronal immaturity were a common finding. Failure of maturation of neuronal precursors caused by altered expression of cytoskeletal proteins and loss of neuronal polarity results in defects in migration to the destined layer and in incorrect vertical and horizontal orientation [93]. The immaturity of dysplastic neurons is reflected in the expression of a variety of proteins and mRNA that are not present in mature neurons an altered expression of developmentally regulated cytoskeletal elements $[3,23,61,76]$, 
which are known to be crucial for dendrite arborization, spine formation, axon outgrowth and maintenance of cell size and shape. Reduced cell size, dendritic arborization and spine expression are characteristic of dysplastic neurons $[6,93]$. Cortical dysplasias are the most epileptogenic lesions of the brain [107] and are observed in up to $25 \%$ of all epileptic surgeries [102]. More subtle cortical malformations or dysgenesis encountered in adults with epilepsy may lack the histological criteria for focal cortical dysplasia. They have been described as mild cortical dysplasia or microdysgenesis [77].

Microdysgenesis within the entorhinal cortex of the 23and the 60-year-old autistic subjects in the examined cohort is unique because the selective deficit of neurons was limited almost exclusively to the stellate neurons in the second layer. It is possible that the observed dysgenesis is a result of defective migration of neurons to their intended destinations. The presence of a thicker molecular layer and the deeper location of islands in the entorhinal cortex of subjects with schizophrenia were previously interpreted as evidence that the stellate neurons do not reach their destinations during development, probably due to abnormal migration $[36,57]$. Studies indicating the involvement of reelin and $\mathrm{Bcl} 2$ genes in the pathogenesis of schizophrenia $[37,47,60]$ and the reduced expression of reelin and Bcl2 in people with autism suggest that these two genes play a role in abnormal brain development and contribute to the structural and functional anomalies seen in autism and schizophrenia [37].

The distortion of dentate gyrus development detected in two autistic subjects was reflected in granule cell migration into the molecular layer and formation of an additional granule cell layer. Distortion of the shape of the dentate granule cell layer with the formation of irregular circles and loops appears to be another piece of evidence suggesting abnormal neuronal migration and networking. Numerous factors up-regulate neurogenesis in the hippocampus [32], including seizures [70, 71], antidepressant drugs [59, 72] and lithium [18]. Several areas of dysplastic changes with significant deficits of pyramidal neurons were found in the CA1 sector in three autistic subjects, but thickening of the pyramidal layer and an increased packing of dysplastic neurons in the CA1 sector of the 56-year-old subject suggests a diversity of CA dysplasia patterns in autism. The lack of gliosis indicates that the observed pathology is a sign of microdysgenesis rather than an effect of hypoxic neuronal loss. A significant deficit of mature pyramidal neurons and the presence of small irregular or poorly differentiated oval neurons suggest the defect of neuronal maturation in autism.

We report a spectrum of focal developmental changes seen in the cerebellum of eight autistic subjects, including nodular (lobe X) [97] dysplasia in the cerebellum in five, vermal dysplasia in one, severe focal hypoplasia in one, and heterotopias in one other subject. The presence of heterotopias only in one control subject is evidence of a strong tendency for focal developmental changes of cerebellar microarchitecture that were present in $61 \%$ of the autistic subjects. Flocculonodular dysplasia affecting almost the entire lobe indicates that mechanisms leading to focal dysplasia, which were present in five $(38 \%)$ of the autistic subjects, show extremely strong topographic predilection. The observed focal dysplasia was associated with profound local disorganization of granule cells, Purkinje cells and molecular layers limited to a small cerebellar compartment receiving major projections from the vestibular complex involved in the oculomotor and postural system. Similar cerebellar dysplastic changes classified as heterotaxias (clusters of poorly organized mixed cells) were identified in $14 \%$ of normal infants but in $83 \%$ of infants with trisomy of different chromosomes [92]. The presence within the dysplastic nodule of both GABAergic Purkinje cells produced from the cerebellar ventricular zone, and the glutamatergic granule neurons produced from the rhombic lip, and the preservation of the cytoarchitecture in the adjacent cerebellar folia suggest that the final steps of migration and networking are disturbed mainly or exclusively in the nodule of the majority of autistic subjects. The characteristic feature distinguishing lobule $\mathrm{X}$ from the other lobules is the abundance of the transcription factor Tbr2 positive unipolar brush cells (UBCs) [30, 34], which amplify inputs from vestibular ganglia and nuclei, by spreading and prolonging excitation within the internal granular layer [84]. Abnormal networking of Purkinje cells, granule neurons, and UBCs may contribute to altered cerebellar coordination of locomotion and motor learning and planning, as well as of higher cognitive processing [58]. Flocculonodular dysplasia appears to be another sign of the mosaic of local developmental defects, most likely predetermined by the spatial patterning of germinal zones in developing rhombic lip [110], and coexisting with more general developmental defects resulting in the accelerated growth of the brain in early childhood [89], minicolumn pathology [13, 14], reduced neuron volume [7, 108, 111], and desynchronized neuronal growth in many brain regions [111] observed in autism.

Identification of sub-groups with signs of hyperplasia, hypoplasia and normal-sized cerebellum [95] reflects the heterogeneity of the autistic population. Piven et al. [87] reported that cerebellar volume correlates with an increased total brain volume. In the majority of autistic subjects, reduced size of the cerebellar hemisphere is observed $[42,82]$, but this trend is not detectable in cohorts of high-functioning autistic individuals [56]. Regional hypoplasia affects the vermis in autistic individuals relatively often $[20,22,52]$ and may be associated with the 
deficits in attention-orienting [49, 104], stereotypic behavior and reduced exploration observed in autism [86]. In the examined autistic cohort, selective and severe hypoplasia of lobes 1-4 associated with hypoconvolution of a large portion of the dentate nucleus appears to correspond to clinically detected defects of movement coordination. These findings suggest that differences in the type, topography and severity of cerebellar developmental defects may contribute to different clinical manifestations.

In the 4-7-year-old autistic children examined in this study, the volume of the Purkinje cells was $38 \%$ smaller than that of the age-matched control group [111]. Moreover, it has been reported that Purkinje cells of the autistic subjects revealed a $40 \%$ decrease in the expression of glutamic acid decarboxylase 67 (GAD67) mRNA [114]. In autism, the basket cells provide an increased GABAergic feed-forward inhibition to Purkinje cells. The result could be disruption in the timing of Purkinje cell firings and altered inhibition of the cerebellar nuclei, which could directly affect cerebello-cortical output and contribute to the changes in motor behavior and cognition observed in autism [115]. These findings and the reduced volume (by $26 \%$ ) of the neurons of the dentate nucleus seen in the 4-7year-old autistic children [111] suggest that in autism, interactions between the Purkinje cells and dentate nucleus are modified on the structural, molecular and functional levels.

The (a) detected changes within the subependymal cell layer with subependymal nodular dysplasia, (b) subcortical and periventricular heterotopias and (c) neocortex, archicortex, dentate gyrus, cornu Ammonis and cerebellar dysplasia reflect focal modification of neurogenesis, migration and alterations of the cytoarchitecture of brain cortex, subcortical structures and cerebellum in autism. Detection of dysplastic changes only in one control brain and of the broad spectrum of focal developmental alterations in the brains of $92 \%$ of the autistic subjects indicates that focal changes are a reflection of global developmental abnormalities and that regional changes may have their own contribution to the clinical heterogeneity of autism.

Acknowledgments This study was supported in part by funds from the New York State Office of Mental Retardation and Developmental Disabilities, a grant from the Department of Defense Autism Spectrum Disorders Research Program (AS073234, Program Project; J.W., T.W., A.C.), a grant from Autism Speaks (Princeton, NJ), and grant R01 HD43960 (J.W.) from the National Institutes of Health, National Institute of Child Health and Human Development. Tissue and clinical records' acquisition was coordinated by the Autism Tissue Program (Princeton, NJ; Directors: Jane Pickett, Ph.D. and Daniel Lightfoot, Ph.D.). The tissue was obtained from the Harvard Brain Tissue Resource Center, Belmont, MA, supported in part by PHS grant number R24-MH 068855; the National Institute of Child Health and Human Development Brain and Tissue Bank for Developmental Disorders at the University of Maryland, Baltimore; and the Brain Bank for Developmental Disabilities and Aging of the New York
State Institute for Basic Research in Developmental Disabilities, Staten Island, NY. We thank Drs. Helmut Hainsen and Christoph Schmitz for help in implementation of the celloidin protocol, and Mrs. Jadwiga Wegiel, Cathy Wang and En Wu Zhang for histology. We are deeply indebted to the families of the tissue donors who have made this study possible.

Open Access This article is distributed under the terms of the Creative Commons Attribution Noncommercial License which permits any noncommercial use, distribution, and reproduction in any medium, provided the original author(s) and source are credited.

\section{References}

1. American Psychiatric Association (2000) Diagnostic and statistical manual of mental disorders DSM-IV-TR. American Psychiatric Association, Washington, DC

2. Andrade DM (2009) Genetic basis in epilepsies caused by malformations of cortical development and in those with structurally normal brain. Hum Genet 126:173-193

3. Avila J, Dominguez J, Diaz-Nido J (1994) Regulation of microtubule dynamics by microtubule-associated protein expression and phosphorylation during neuronal development. Int J Dev Biol 38:13-25

4. Bailey AP, Luthert A, Dean B et al (1998) A clinicopathological study of autism. Brain 121:889-905

5. Bailey AR, Giunta BN, Obregon D et al (2008) Peripheral biomarkers in autism: secreted amyloid precursor protein-alpha as a probable key player in early diagnosis. Int J Clin Exp Med $1: 338-344$

6. Barth PG (1987) Disorders of neuronal migration. Can J Neurol Sci 14:1-16

7. Bauman ML, Kemper TL (1985) Histoanatomic observations of the brain in early infantile autism. Neurology 35:866-867

8. Baybis M, Yu J, Lee A, Golden JA et al (2004) mTOR cascade activation distinguishes tubers from focal cortical dysplasia. Ann Neurol 56:478-487

9. Bobinski M, de Leon MJ, Convit A et al (1999) MRI of entorhinal cortex in mild Alzheimer's disease. Lancet 353:38-40

10. Boddaert N, Zilbovicius M, Philipe A et al (2009) MRI findings in 77 children with non-syndromic autistic disorder. PLoS One 4:e4415

11. Bruce S, Nyberg F, Melén E et al (2009) The protective effect of farm animal exposure on childhood allergy is modified by NPSR1 polymorphisms. J Med Genet 46:159-167

12. Carlson BA, Houser OW, Gomez MR (1999) Brain imaging in the tuberous sclerosis complex. In: Gomez M, Sampson J, Whittemore V (eds) Tuberous sclerosis complex, 3rd edn. Oxford University Press, New York, pp 85-93

13. Casanova MF, Buxhoeveden DP, Switala AE, Roy E (2002) Minicolumnar pathology in autism. Neurology 58:428-432

14. Casanova MF, van Kooten IAE, Switala EH et al (2006) Minicolumnar abnormalities in autism. Acta Neuropathol 112:287-303

15. Caspi M, Atlas R, Kantor A, Sapir T, Reiner O (2000) Interaction between LIS1 and doublecortin, two lissencephaly gene products. Hum Mol Genet 9:2205-2213

16. Chang BS, Walsh CA (2009) The genetic basis of human cerebral cortical malformations. In: Runge MS, Patterson C (eds) Principles of molecular medicine. Human Press Inc, Totowa, NJ, pp 1073-1079

17. Chauhan A, Chauhan V (2006) Oxidative stress in autism. Pathophysiology 13:171-181 
18. Chen G, Rajkowska G, Du F, Seraji-Bozorgzad N, Manji NH (2000) Enhancement of hippocampal neurogenesis by lithium. J Neurochem 75:1729-1734

19. Chow TW, Cummings JL (1999) Frontal-subcortical circuits. In: Miller BL, Cummings JL (eds) The human frontal lobes: functions and disorders. Guilford Press, New York, pp 3-26

20. Ciesielski KT, Harris RJ, Hart BL, Pabst H (1997) Cerebellar hypoplasia and frontal lobe cognitive deficits in disorders of early childhood. Neuropsychologia 35:643-655

21. Courchesne E, Hesselink JR, Jernigan TL, Yeung-Courchesne R (1987) Abnormal neuroanatomy in a nonretarded person with autism. Unusual findings with magnetic resonance imaging. Arch Neurol 44:335-341

22. Courchesne E, Yeung-Courchesne R, Press GA, Hesselink JR, Jernigan TL (1988) Hypoplasia of cerebellar vermal lobules VI and VII in autism. N Engl J Med 318:1349-1354

23. Crino PB, Trojanowski JQ, Eberwine J (1997) Internexin, MAP1B, and nestin in cortical dysplasia as markers of developmental maturity. Acta Neuropathol 93:619-627

24. Crino PB, Henske EP (1999) New developments in the neurobiology of the tuberous sclerosis complex. Neurology 53:13841390

25. Crino PB, Miyata H, Vinters HV (2002) Neurodevelopmental disorders as a cause of seizures: neuropathologic, genetic, and mechanistic considerations. Brain Pathol 12:212-233

26. Curtis MA, Penney EB, Pearson J, Dragunow M, Connor B, Faull RL (2005) The distribution of progenitor cells in the subependymal layer of the lateral ventricle in the normal and Huntington's disease human brain. Neuroscience 132:777-788

27. Damasio H, Maurer RG, Damasio AR, Chui HC (1980) Computerized tomographic scan findings in patients with autistic behavior. Arch Neurol 37:504-510

28. Department of Health and Human Services (2007) Morbidity and mortality weekly report. In: Department of Health and Human Services, Centers for Disease Control and Prevention, pp 1-28

29. des Portes V, Francis F, Pinard JM et al (1998) Doublecortin is the major gene causing $\mathrm{X}$-linked subcortical laminar heterotopia (SCLH). Hum Mol Genet 7:1063-1070

30. Diño MR, Willard FH, Mugnaini E (1999) Distribution of unipolar brush cells and other calretinin immunoreactive components in the mammalian cerebellar cortex. J Neurocytol 28:99-123

31. Dubeau F, Tampieri D, Lee N et al (1995) Periventricular and subcortical nodular heterotopia: a study of 33 patients. Brain 118:1273-1287

32. Duman RS, Nakagawa S, Malberg J (2001) Regulation of adult neurogenesis by antidepressant treatment. Neuropsychopharmacology 25:836-844

33. Eriksson PS, Perfilieva E, Bjork-Eriksson T et al (1998) Neurogenesis in the adult human hippocampus. Nat Med 4:13131317

34. Englund C, Kowalczyk T, Daza RAM et al (2006) Unipolar brush cells of the cerebellum are produced in the rhombic lip and migrate through developing white matter. J Neurosci 26:9184-9195

35. Ess KC, Kamp CA, Tu BP, Gutmann DH (2005) Developmental origin of subependymal giant cell astrocytoma in tuberous sclerosis complex. Neurology 64:1446-1449

36. Falkai P, Schneider-Axmann T, Honer WG (2000) Entorhinal cortex pre-alpha cell clusters in schizophrenia: quantitative evidence of a developmental abnormality. Biol Psychiatry 47:937-943

37. Fatemi SH, Kroll JL, Stary JM (2001) Altered levels of Reelin and its isoforms in schizophrenia and mood disorders. Neuroreport 12:3209-3215
38. Fatemi SH, Stary JM, Halth AR, Realmuto GR (2001) Dysregulation of reelin and Bcl-2 proteins in autistic cerebellum. J Autism Dev Disord 31:529-535

39. Fox JW, Lamperti ED, Eksioglu YZ (1998) Mutations in filamin 1 prevent migration of cerebral cortical neurons in human periventricular heterotopia. Neuron 21:1315-1325

40. Fuh JL, Wang SJ (1995) Caudate hemorrhage: clinical features, neuropsychological assessments and radiological findings. Clin Neurol Neurosurg 97:296-299

41. Gabriels RL, Cuccaro ML, Hill DE, Ivers BJ, Goldson E (2005) Repetitive behaviors in autism: relationships with associated clinical features. Res Dev Disabil 26:169-181

42. Gaffney GR, Tsai LY, Kuperman S, Minchin S (1987) Cerebellar structure in autism. Am J Dis Child 141:1330-1332

43. Gillberg C, Coleman M (1996) Autism and medical disorders: a review of the literature. Dev Med Child Neurol 38:191-202

44. Gleeson JG, Allen KM, Fox JW (1998) Doublecortin, a brainspecific gene mutated in human X-linked lissencephaly and double cortex syndrome, encodes a putative signaling protein. Cell 92:63-72

45. Gleeson JG, Lin PT, Flanagan LA, Walsh CA (1999) Doublecortin is a microtubule-associated protein and is expressed widely by migrating neurons. Neuron 23:257-271

46. Gorlin JB, Henske E, Warren ST (1993) Actin-binding protein (ABP-280) filamin gene (FLN) maps telomeric to the color vision locus (R/GCP) and centromeric to G6PD in Xq28. Genomics 17:496-498

47. Guidotti A, Auta J, Davis JM (2000) Decrease in reelin and glutamic acid decarboxylase67 (GAD67) expression in schizophrenia and bipolar disorder: a postmortem brain study. Arch Gen Psychiatry 57:1061-1069

48. Happe F, Ronald A, Plomin R (2006) Time to give up on a single explanation for autism. Nat Neurosci 9:1218-1220

49. Harris NS, Courchesne E, Townsend J, Carper RA, Lord C (1999) Neuroanatomic contributions to slowed orienting of attention in children with autism. Brain Res Cogn Brain Res 8:61-71

50. Hashimoto T, Tayama M, Mori K, Fujino K, Miyazaki M, Kuroda Y (1989) Magnetic resonance imaging in autism: preliminary report. Neuropediatrics 20:142-146

51. Hashimoto T, Tayama M, Miyazaki M, Murakawa K, Kuroda Y (1993) Brainstem and cerebellar vermis involvement in autistic children. J Child Neurol 8:149-153

52. Hashimoto T, Tayama M, Murakawa K et al (1995) Development of the brainstem and cerebellum in autistic patients. J Autism Dev Disord 25:1-18

53. Heinsen H, Arzberger T, Schmitz C (2000) Celloidin mounting (embedding without infiltration) — a new, simple and reliable method for producing serial sections of high thickness through complete human brains and its application to stereological and immunohistochemical investigations. J Chem Neuroanat 20:4959

54. Herbert MR, Ziegler DA, Deutsch CK (2003) Dissociations of cerebral cortex, subcortical and cerebral white matter volumes in autistic boys. Brain 126:1182-1192

55. Hollander E, Anagnostou E, Chaplin W (2005) Striatal volume on magnetic resonance imaging and repetitive behaviors in autism. Biol Psychiatry 58:226-232

56. Holttum JR, Minshew NJ, Sanders RS, Phillips NE (1992) Magnetic resonance imaging of the posterior fossa in autism. Biol Psychiatry 32:1091-1101

57. Honer WG, Bassett AS, Falkai P, Beach TG, Lapointe JS (1996) A case study of temporal lobe development in familial schizophrenia. Psychol Med 26:191-195

58. Ito M (2008) Control of mental activities by internal models in the cerebellum. Nat Rev Neurosci 9:304-313 
59. Jacobs BL, Fornal CA (1999) Activity of serotonergic neurons in behaving animals. Neuropsychopharmacology 21:9S-15S

60. Jarskog LF, Gilmore JH, Selinger ES, Lieberman JA (2000) Cortical bcl-2 protein expression and apoptotic regulation in schizophrenia. Biol Psychiatry 48:641-650

61. Kaplan MP, Chin SS, Fliegner KH, Liem RK (1990) Alphainternexin, a novel neuronal intermediate filament protein, precedes the low molecular weight neurofilament protein (NF-L) in the developing rat brain. J Neurosci 10:2735-2748

62. Kemper TL (1988) Neuroanatomic studies of dyslexia and autism. In: Disorders of the developing nervous system: changing views on their origins, diagnosis, and treatments. Alan R. Liss Inc, New York, pp 125-154

63. Kemper TL, Bauman ML (1993) The contribution of neuropathologic studies to the understanding of autism. Behav Neurol 11:175-187

64. Kemper TL, Bauman M (1998) Neuropathology of infantile autism. J Neuropathol Exp Neurol 57:645-652

65. Kremer S, De Saint MA, Minotti L et al (2002) Focal cortical dysplasia possibly related to a probable prenatal ischemic injury. J Neuroradiol 29:200-203

66. Langen M, Durston S, Staal WG, Palmen SJ, van Engelan H (2007) Caudate nucleus is enlarged in high-functioning medication-naive subjects with autism. Biol Psychiatry 62:262266

67. Lee A, Maldonado M, Baybis M et al (2003) Markers of cellular proliferation are expressed in cortical tubers. Ann Neurol 53:668-673

68. Lopez-Hurtado E, Prieto JJ (2008) A microscopic study of language-related cortex in autism. Am J Biochem Biotechnol 4:130-145

69. Lord C, Risi S, Lambrecht L et al (2000) The autism diagnostic observation schedule-generic: a standard measure of social and communication deficits associated with the spectrum of autism. J Autism Dev Disord 30:205-223

70. Madsen TM, Treschow A, Bengzon J, Bolwig TG, Lindvall O, Tingstrom A (2000) Increased neurogenesis in a model of electroconvulsive therapy. Biol Psychiatry 47:1043-1049

71. Malberg JE, Eisch AJ, Nestler EJ, Duman RS (2000) Chronic antidepressant treatment increases neurogenesis in adult rat hippocampus. J Neurosci 20:9104-9110

72. Manev H, Uz T, Smalheiser NR, Manev R (2001) Antidepressants alter cell proliferation in the adult brain in vivo and in neural cultures in vitro. Eur J Pharmacol 411:67-70

73. Marcotte L, Crino PB (2006) The neurobiology of the tuberous sclerosis complex. Neuromol Med 8:531-546

74. Marin-Padilla M, Parisi JE, Armstrong DL, Sargent SK, Kaplan JA (2002) Shaken infant syndrome: developmental neuropathology, progressive cortical dysplasia, and epilepsy. Acta Neuropathol 103:321-332

75. Marshall CR, Noor A, Vincent JB et al (2008) Structural variation of chromosomes in autism spectrum disorder. Am $\mathrm{J}$ Human Gen 82:477-488

76. Matus A (1988) Microtubule-associated proteins: their potential role in determining neuronal morphology. Ann Rev Neurosci 11:29-44

77. Meencke HJ, Janz D (1985) The significance of microdysgenesia in primary generalized epilepsy: an answer to the considerations of Lyon and Gastaut. Epilepsia 26:368-371

78. Mendez MF, Adams NL, Lewandowski KS (1989) Neurobehavioral changes associated with caudate lesions. Neurology 39:349-354

79. Miles JH, Takahashi TN, Bagby S et al (2005) Essential versus complex autism: definition of fundamental prognostic subtypes. Am J Med Genet A 135:171-180
80. Miyata H, Chiang AC, Vinters H (2004) Insulin signaling pathways in cortical dysplasia and TSC-tubers: tissue microarray analysis. Ann Neurol 56:510-519

81. Muller RA (2007) The study of autism as a distributed disorder. Ment Retard Dev Disabil Res Rev 13:85-95

82. Murakami W, Courchesne E, Press GA, Yeung-Courchesne R, Hesselink JR (1989) Reduced cerebellar hemisphere size and its relationship to vermal hypoplasia in autism. Arch Neurol 46:689-694

83. Newschaffer CJ, Fallin D, Lee NL (2002) Heritable and nonheritable risk factors for autism spectrum disorders. Epidemiol Rev 24:137-153

84. Nunzi MG, Birnstiel S, Bhattacharyya BJ, Slater NT, Mugnaini E (2001) Unipolar brush cells form a glutamatergic projection system within the mouse cerebellar cortex. J Comp Neurol 434:329-341

85. Palmen SJ, van Engelan H, Hof PR, Schmitz C (2004) Neuropathological findings in autism. Brain 127:2572-2583

86. Pierce K, Courchesne E (2001) Evidence for a cerebellar role in reduced exploration and stereotyped behavior in autism. Biol Psychiatry 49:655-664

87. Piven J, Saliba K, Bailey J, Arndt S (1997) An MRI study of autism: the cerebellum revisited. Neurology 49:546-551

88. Poldrack RA, Prabhakaran V, Seger CA, Gabrieli JD (1999) Striatal activation during acquisition of a cognitive skill. Neuropsychology 13:564-574

89. Redcay E, Courchesne E (2005) When is the brain enlarged in autism? A meta-analysis of all brain size reports. Biol Psychiatry 58:1-9

90. Ritvo ER, Freeman BJ, Scheibel AB et al (1986) Lower Purkinje cell counts in the cerebella of four autistic subjects: initial findings of the UCLA-NSAC Autopsy Research Report. Am J Psychiatry 143:862-866

91. Rodier PM, Ingram JL, Tisdale B, Nelson S, Romano J (1996) Embryological origin of autism: developmental abnormalities of the cranial nerve nuclei. J Comp Neurol 370:247-261

92. Rorke LB, Fogelson MH, Riggs HE (1968) Cerebellar heterotopia in infancy. Dev Med Child Neurol 10:644-650

93. Rorke LB (1994) A perspective: the role of disordered genetic control of neurogenesis in the pathogenesis of migration disorders. J Neuropathol Exp Neurol 53:105-117

94. Rutter M, Bailey A, Bolton P, Le Couteur A (1994) Autism and known medical conditions: myth and substance. J Child Psychol Psychiatry 35:311-322

95. Saitoh O, Courchesne E (1998) Magnetic resonance imaging study of the brain in autism. Psychiatry Clin Neurosci 52(Suppl):S219-S222

96. Sarnat HB, Benjamin DR, Siebert JR et al (1992) Cerebral dysgenesis: embryology and clinical expression. Cell 69:581595

97. Schmahmann JD, Doyon J, McDonald D et al (1999) Threedimensional MRI atlas of the human cerebellum in proportional stereotaxic space. Neuroimage 10:233-260

98. Schmidtke K, Manner H, Kaufmann R, Schmolck H (2002) Cognitive procedural learning in patients with fronto-striatal lesions. Learn Mem 9:419-429

99. Sears LL, Vest C, Mohamed S, Bailey J, Ranson BJ, Piven J (1999) An MRI study of the basal ganglia in autism. Prog Neuropsychopharmacol Biol Psychiatry 23:613-624

100. Simms ML, Kemper TL, Timbie CM, Bauman ML, Blatt GJ (2009) The anterior cingulate cortex in autism: heterogeneity of qualitative and quantitative cytoarchitectonic features suggests possible subgroups. Acta Neuropathol 118:673-684

101. Sokol DK, Chen D, Farlow MR et al (2006) High levels of Alzheimer beta-amyloid precursor protein (APP) in children 
with severely autistic behavior and aggression. J Child Neurol 21:444-449

102. Tassi L, Colombo N, Garbelli R et al (2002) Focal cortical dysplasia: neuropathological subtypes, EEG, neuroimaging and surgical outcome. Brain 125:1719-1732

103. The Autism Genome Project Consortium (2007) Mapping autism risk loci using genetic linkage and chromosomal rearrangements. Nat Genet 39:319-328

104. Townsend J, Courchesne E, Covington J et al (1999) Spatial attention deficits in patients with acquired or developmental cerebellar abnormality. J Neurosci 19:5632-5643

105. Tuchman RF, Rapin I, Shinnar S (1991) Autistic and dysphasic children. I. Clinical characteristics. Pediatrics 88:1211-1218

106. Tuchman RF, Rapin I (2002) Epilepsy in autism. Lancet Neurol $1: 352-358$

107. Usui N, Matsuda K, Mihara T et al (2001) MRI of cortical dysplasia-correlation with pathological findings. Neuroradiology 43:830-837

108. van Kooten I, Palmen SJ, von Engelan CP et al (2008) Neurons in the fusiform gyrus are fewer and smaller in autism. Brain 131:987-999

109. Voelbel GT, Bates ME, Buckman JF, Pandina G, Hendren RL (2006) Caudate nucleus volume and cognitive performance: are they related in childhood psychopathology? Biol Psychiatry 60:942-950
110. Volkmann K, Rieger S, Babaryka A, Koster RW (2008) The zebrafish cerebellar rhombic lip is spatially patterned in producing granule cell populations of different functional compartments. Dev Biol 313:167-180

111. Wegiel J, Wisniewski T, Chauhan A (2010) Type, topography and sequelae of neuropathological changes shaping clinical phenotype of autism. In: Chauhan A, Chauhan V, Brown WT et al (eds) Autism: oxidative stress, inflammation, and immune abnormalities. Taylor \& Francis/CRC Press, Boca Raton, FL, pp $1-34$

112. Weiss LA, Arking DE, The Gene Discovery Project of Johns Hopkins \& the Autism Consortium (2009) A genome-wide linkage and association scan reveals novel loci for autism. Nature 461:802-811

113. Wolf HK, Normann S, Green AJ et al (1997) Tuberous sclerosislike lesions in epileptogenic human neocortex lack allelic loss at the TSC1 and TSC2 regions. Acta Neuropathol 93:93-96

114. Yip J, Soghomonian JJ, Blatt GJ (2007) Decreased GAD67 mRNA levels in cerebellar Purkinje cells in autism: pathophysiological implications. Acta Neuropathol 113:559-568

115. Yip JJ, Soghomonian J, Blatt GJ (2008) Increased GAD67 mRNA expression in cerebellar interneurons in autism: implications for Purkinje cell dysfunction. J Neurosci Res 86:525530 